\title{
Encouraging Lifelong Learning: An Educator's Perspective on Teaching and Learning for the Nuclear Medicine Technologist
}

\author{
Isabel T. Breen, $\mathrm{PhD}, \mathrm{RT}(\mathrm{N})$
}

Nuclear Medicine Technology Program, Department of Clinical Laboratory Sciences and Medical Imaging, School of Health

Professions, Rutgers University, Newark, New Jersey

Knowledge of the methods alone will not suffice; there must be the desire, the will, to employ them. This desire is an affair of personal disposition.

—John Dewey (1933)

The rapid influx of new technology and changing reimbursement and health care business models challenge nuclear medicine technology educators to reexamine the effectiveness of traditional teaching methods. As a generation of technologists can attest, the skill sets and competencies taught today will not be the requirements of tomorrow. The question arises, "How can educators prepare students and the profession for future knowledge capacity?" The concept of lifelong learning (LLL) emerged in the 1970s as a response to the global paradigm shift from an industrial society to a knowledge society. Given the current health care climate and the dynamic nature of the nuclear medicine technology profession, understanding and development of LLL assessment models may benefit both teacher and student learning. This article discusses the theoretic framework of LLL and social learning along with a sampling of teaching assessments. These assessments use a problembased-learning approach that integrates the concepts of LLL into an accountability-driven social organization.

Key Words: learning capacity; problem-based learning; selfefficacy; self-reflection; student-centered learning

J Nucl Med Technol 2019; 47:120-126

DOI: 10.2967/jnmt.118.218545

\section{$\mathbf{E}$} merging new technology development and new business models dictate that any professional practice standard responds to the constant flux in today's organizations (1). The health care industry and, specifically, nuclear medicine technology (NMT) are no exception. An article in Forbes entitled "The Future of your Career Depends on Lifelong Learning" highlights the professional perspective of necessary career attributes for long-term success (2). A salient

\footnotetext{
Received Jul. 25, 2018; revision accepted Oct. 29, 2018.

For correspondence or reprints contact: Isabel T. Breen, Rutgers University, Stanley S. Bergen Building, GB 23, 65 Bergen St., Newark, NJ 07101.

E-mail: itb11@shp.rutgers.edu

Published online Nov. 9, 2018

COPYRIGHT (c) 2019 by the Society of Nuclear Medicine and Molecular Imaging.
}

insight in this article describes the effects of automation and artificial intelligence in a new "gig" economy as the driver for self-directed, renewable learning necessary in the workplace. Nuclear medicine is no stranger to the rapid technologic developments in the field, changes in the policy and reimbursement environment, and the gig economy in which employers hire per-diem contract employees rather than full-time technologists. Miller and Gallachio (3) described the increasingly complex, accelerated changes in allied health care delivery models, such as professional accountability, technologic developments, globalization, and policies, while emphasizing the need for an empowered allied health workforce. Mastery of change now becomes a critical element in health care as complex systems thinking surpasses linear thinking (3).

The concept of lifelong learning (LLL) addresses the very issues of complexity and learning power ascribed above as necessary for any 21 st century career, including nuclear medicine. NMT education includes both didactic and clinical components. Because of the accountability and standard-driven requirements within the NMT education process, didactic coursework typically includes a linear, sequential curriculum approach. Clinical training introduces students to the complexities within the health care organization. Knight previously described the unpredictable and stressful nature of NMT clinical training (4). The LLL model presents a learning approach for subject-driven, didactic NMT courses that may serve as a bridge between the didactic and clinical experience. In addition to clinical instruction, problem-based-learning (PBL) assessments provide students with real-world practice in capacity building, the foundation of LLL. Incorporating and encouraging LLL in a college classroom involves a shift from the classic adultlearning andragogy to the more learner-centered application of heutagogy.

Andragogy was described by Knowles as the art and science of teaching adults (5). The main premise is that adults learn differently from children. Andragogy assumes adults are typically independent, self-directed learners. Teachers 
function as the facilitator in the learning process. Heutagogy is the study of self-determination (6). Heutagogic teaching models are associated with both self-efficacy and self-determination theories. The focus of curriculum assessment is shifted from teacher-centered to learner-centered, expanding the goal of learning from competence to learner capacity. The application of heutagogy involves the practice of reflective thinking and is well suited for the challenges presented within an NMT professional education. Both the technologic aspects for national certification and the interpersonal and social characteristics of the NMT profession are considered. The purpose of this paper is to provide an overview of selected literature on LLL while describing its potential for student engagement in current and future learning environments. The theoretic framework is discussed followed by constructs and definitions attributed to LLL. Examples of personal classroom application of LLL assessments are added for a further description.

\section{LEARNING THEORIES IN A SOCIAL COMPLEX SYSTEM}

An array of learning theories has described the various constructs of attributes that contribute to effective learning dispositions. The now commonly used phrase Pavlov's dogs formed the foundation for behavioral conditioning and conditioned responses. Cognitive theory focuses on the mental processes within human development. Both early classical theories assumed a teacher-centered learning approach. Essentially, the teacher gave knowledge and students received the subject matter while the socioemotional aspects of learning were ignored.

Bandura's groundbreaking work in social cognitive theory departed from the behavioral and cognitive theorists' unidimensional approach to human development and learning (7). Rather than a specific cause-and-effect conditioned response to either environmental or personal stimuli, Bandura explained human ability through a social cognitive lens. Bandura's model established a series of learning dispositions that showed the reciprocal interactions between the learner and the social environment. Learners develop different strengths and exhibit different learning behaviors as a result of these interactions with the social environment. The dimensions include behavior, personal cognition, and environmental factors that influence development in a bidirectional, dynamic manner rather than being a simple unidirectional cause-and-effect phenomenon. This phenomenon corresponds directly to the reflective process used in heutagogy and LLL. The focus of learning shifts from "what to learn" to "how to learn." The influence of social and environmental factors changes in the strength of effect through the distinctly human characteristics of evaluative self-regulation and reflective self-consciousness. Selfappraisals of feedback and outcomes determine individual actions and provide the foundation for effective LLL and goal attainment. Consequently, learning and growth are viewed as a dynamic process in which an individual evaluates environmental and psychologic influences and responds accordingly based on his or her individual reactions to the stimuli. Performance discrepancies contribute to the personal adjustments made in personal goal setting and persistence throughout the learning process.

Social cognitive theory further distinguishes an individual's outcome expectancies from efficacy expectancies. Learners may possess the appropriate cognitive skills for outcome achievement but may not believe they are able to succeed. In other words, even bright, capable students may fear the challenge of unfamiliar NMT concepts. Efficacy has demonstrated predictive value for goal setting and motivation for students, teachers, and organizational entities. The aforementioned fear may diminish a student's academic performance. Subsequently, these diminished expectations may affect the overall organizational culture of the classroom.

Consistent with a systems approach, organizational entities exhibit human characteristics that represent the organizational culture (7). Consequently, organizational behavior including classroom organization, may influence individual human ability and outcome expectancies. From a practical viewpoint, organizational practices in the classroom may be used to mimic the interpersonal nature of the clinical experience. When an educator understands the fear and apprehension a student may have of the unknown, the notion of positive affective professional behavior reinforcement can be introduced into the curriculum. The assessments described later in this paper serve as an example for simulating the stressful and unpredictable nature of clinical assignments. This, in turn, may improve a student's efficacy beliefs for success in the clinical environment.

Self-efficacy beliefs function as important determinants of human ability, which is a variable attribute based on the selforganization of cognitive, motivational, social, and behavioral skills (7). The social cognitive theory posits that self-appraisals of feedback and outcomes determine individual actions. Selfefficacy is the personal regard individuals have in their capabilities to overcome and persist in challenging or adverse conditions. Specifically, a student's emotional response to an instructor's feedback may affect performance as strongly as individual cognitive ability. The NMT educator's awareness of the origins of self-efficacy serves as an essential tool for student development and professional success.

In his seminal work, Bandura defined the following sources of efficacy expectations (7): performance accomplishments, vicarious experience, verbal persuasion, and emotional arousal.

Repeated successes have been identified as the most influential source of self-efficacy and mastery performance. Additionally, participant observation of successful mastery by others also contributes to an individual's belief in his or her capabilities. The third source, verbal persuasion, can often induce a sense of efficacy in another; this source is viewed as the weakest influence on self-efficacy beliefs. People also rely on emotional reactions, such as stress, fear, or anxiety, in forming perceptions of self-efficacy.

Previous research has demonstrated that the socioemotional aspects of learning influence both student and instructor success, yet these aspects are seldom reflected within 
content-driven student outcomes (7). Students may become competent in learning NMT content yet experience stress and fear in their clinical training (4). The importance of selfefficacy is exemplified in the cognitive and socioemotional learning capacity during the transition from classroom to clinic. Developing assessments with an understanding of the sources of self-efficacy facilitates a student's belief in his or her learning abilities and assists in the development of learning capacity. This learning capacity is the hallmark of LLL, in which knowledge is transferred to new learning environments.

\section{WHAT IS LLL?}

LLL emerged in the 1970 s as a critical element for success in the global transition from the industrial society to the knowledge society. In the 1990s, the European Commission, the Organization for Economic Cooperation and Development, and the United Nations released publications that placed LLL as a societal trend with not only educational implications but also economic implications for the 21st century worker (8). Several definitions exist for LLL. Harper Collins dictionary defines LLL as the "provision or use of both formal and informal learning opportunities throughout people's lives in order to foster the continuous development and improvement of the knowledge and skills needed for employment and personal fulfillment" (9). Other definitions include key terms, such as continuous learning in times of rapid change, a broad concept of a flexible and diverse education, an essential means of assimilating new technology not limited to formal education, and others (10). The natural progression of LLL in worldwide applications within a knowledge society included the formal research characterization of the specific attributes of effective learning. Researchers sought to identify how to learn and adapt in a society that was changing rapidly. The resulting assessment theorized that learning competencies are essentially more complex than a definition of learning styles.

Learning styles imply a preference for a fixed learning approach without regard to the social, historical, cultural, and personal resources available in a complex learning journey (11). The Effective Lifelong Learning Inventory was designed as a measurement tool that embodied both the cognitive and the affective aspects of learning. The inventory incorporated Vygotsky's notion of "perezhivani," which is loosely defined as the social situation in development or life's experience. The subsequent self-report questionnaire reflected both cognitive and affective characteristics of a student's personal and social environment. The study focused on the following 7 dimensions of "the power to learn": changing and learning (recognizing that learning itself is learnable), critical curiosity (having the energy and desire to find things out), meaning making (looking for links between what is being learned and what is already known), dependence and fragility (being risk-averse vs. resilient), creativity (imagining possibilities), learning relationships (being interdependent; able to learn in isolation and with others), and strategic awareness (being metacognitive; willing to try different approaches to learning; self-reflective and self-evaluating) (11).
The relationship between these dimensions and the environmental and social context of learning forms a reciprocal feedback loop that defines an individual's purposeful agency. In an effort to identify the strength of these relationships and account for the interrelationships among discrete variables, Effective Lifelong Learning Inventory researchers further reexamined learning power within the framework of systems theory. The dynamic, complex structure of learning operates as "a group of parts that interact so that the system as a whole can do things the parts can't do on their own" (12).

Individual learning becomes part of a social organization in which individual learners develop mindful agency through a dynamic social process model containing iterative feedback loops.

The research authors criticize the singular use of highstakes assessments as a demotivating factor in a student's learning agency and self-determination. "Teachers or learning facilitators can have a direct influence on the context of learning; they can scaffold the processes of knowledge structuring and increasing awareness of learning power, whilst agency cannot be imposed or conferred by other people. Rather it is an emergent property of the recursive interactions between self and context" (12). This constructive approach to teaching and learning serves as a motivational strategy within the uncertainty of a dynamic learning environment.

In a recent Journal of Nuclear Medicine Technology article, Knight outlined the unpredictable nature of a nuclear medicine student's clinical experience. Knight also noted the potential for a demotivating clinical experience ensuing from counterproductive clinical instructor teaching behavior (4). From a practical perspective as an NMT educator, consideration of a student's socioemotional learning preferences as a clinical placement criterion may be critical in a student's academic and career achievements. Placing students within a clinical social learning environment conducive to their individual learning dispositions and the clinical department's organizational disposition is a positive determinant for successful transition to the clinical experience. Accordingly, exploring clinical placements through the lens of LLL presents opportunities for didactic classroom strategies that prepare students for the unpredictability and possible chaos of a clinical environment.

My efforts in experimenting with a variety of assessments resulted in a mix of failures and successful teaching and learning. Using this approach entails a willingness to try new strategies that correlate directly with interdependent learning and strategic awareness. Additionally, an instructor's disposition in the practice of self-reflection requires an inclination to accept feedback from students and retain a flexible teaching approach. Modeling LLL behaviors, especially when admitting mistakes, allows students opportunities for growth while learning positive self-reflective behaviors. The reciprocal nature of the student-teacher feedback mechanisms develops learning power and further models LLL behaviors. 


\section{PROMOTING LLL}

Instructors will encounter a dynamic continuum of learning dispositions among themselves and the students they teach. Along with social, cultural, and demographic differences in a given classroom, learning style preferences indicate a need for diverse teaching and learning strategies in allied health teaching and learning (13). Didactic classroom experiences typically follow the teacher-centered model of passively exchanging knowledge through a series of PowerPoints, lectures, and summative testing. Ideally, a classroom laboratory affords students an introduction to the experiential nature of clinical work in a nuclear medicine department but may not model the general uncertainty associated with a clinical internship. As the student moves into the clinical setting, the social dynamics of the learning organization change along with the individual student's personal learning power. The clinical experience often becomes more stressful than the didactic environment, potentially changing a student's selfefficacy beliefs and knowledge-building capacity.

This change in learning power from the didactic to the clinical experience may be explained using chaos theory. The theory posits that small changes in a nonlinear complex system may produce large effects (14). Historically, the classroom structure resembles the traditional, theoretic approach to linear knowledge acquisition. Knowledge is presented by the instructor, and the student accepts the knowledge as a given fact. During the student transition into a complex clinical setting, the irregularities in learning present as chaos. Rather than viewing the nuclear medicine instructional system (clinical vs. didactic) as discrete systems, chaos theory embraces the complexities and irregularities between the knowledge transmission strategies. Each individual subject-matter course builds a foundation for the holistic practice of NMT. As students gain more clinical experience, they begin the process of meaning-making, connecting subjects and gaining insight into the breadth of nuclear medicine practice. Chaos theory delivers a useful link, with theory-to-practice research highlighting the incremental effects of the affective variables on learning within a complex social learning organization (14). The conflict between the cognitive and socioemotional aspects of the NMT professional education, associated with the transition from didactic to clinical training, may impede a student's capacity for knowledge transfer and critical thinking.

Kantar discussed the conflicts associated with teaching assessments for higher-order thinking with the common belief "that the primary purpose of assessment is assessing content on board examinations" (15). Further conflicts with the tenets of LLL lie in the "what to learn" approach rather than the "how to learn" approach driving standards-driven assessments that further the gap between instruction and learning. Critical thinking and other previously mentioned attributes of LLL require a reciprocal relationship between the components of a well-designed curriculum, content, instruction, and assessment. The student clinical experience benefits when problem solving and coping strategies are introduced in the didactic portion of a health care education. In essence, allow for some controlled chaos in curriculum planning and outcome assessment to bridge the gap between theory and practice.

\section{Summative and Formative Assessment}

Closing the gap begins with an evaluation of the curriculum design, specifically the assessments used to measure student achievement. Summative and formative assessments capture 2 different aspects of student learning, and the resulting data offer 2 different pieces of the instructional feedback loop (16). Summative assessments are cumulative, graded, high-stakes assessments that occur at the end of instruction. For example, final examinations, national certification examinations, and performance-based assessments measure students' level of proficiency and promote critical thinking skills while providing a fair measure of student achievement and programmatic accountability data. In contrast, formative assessment serves as a feedback mechanism that evaluates both teaching and learning.

The goal of formative assessment is to improve learning, whereas summative evaluation measures content mastery and student achievement at a given time. Low-stakes formative assessment allows for teacher intervention in the learning process without penalizing a student for learning. Examples may include ungraded homework, question-andanswer periods, group discussions, and self-reflection journals. Although instructors may use 1 of the 2 assessments at a given time, they are not mutually exclusive. Graded quizzes, homework, and tests during the course of a content lesson allow students a springboard for reflection on improvement areas and provide feedback to instructors on the extent of acquired knowledge. Conversely, assigned projects such as short, ungraded content presentations or takehome tests at the end of a lesson serve as preparation for final examinations.

Each assessment has merit and instructional value for assessing effective learning and complements each other as a teaching and learning strategy. The choice of assessment is directly associated with the desired goal of the chosen assessment. Specifically, the instructor must determine whether the goal is content learning and subject knowledge or the development of effective learning attributes for LLL. Ideally, learning goals include both facets of assessment. Instructors may choose a mix of assessments and assign both low-stakes and high-stakes weighted values, participation credit, or extra credit as tools in LLL development.

\section{Problem-Based Learning}

With respect to bridging the gap between didactic content knowledge and clinical skills, professionalism and its associated attributes require examination. Collaboration, effective communication, conflict management, coping skills, problem solving, and ethical decision making are a few of the attributes that describe professional behavior. The Nuclear Medicine Technologist Scope of Practice standards include the exercise of good judgment in the standards of 
patient care (17). In addition to content curriculum standards, the Joint Review Committee on Educational Programs in Nuclear Medicine Technology requires the development of personal and professional clinical practice attributes, including problem solving, critical thinking, interprofessional health care team skills, respect for diversity, and demonstration of responsibility and ethical principles (18). Throughout the teaching and learning literature, PBL is endorsed as an engaging strategy for effective learning and critical thinking. PBL was initially designed as a corrective teaching strategy for medical students who graduated with "a plenitude of information but without the critical reasoning skills to use that information wisely" (19).

Since its inception, PBL has evolved into an interdisciplinary approach to learning. The key to PBL and its contribution to LLL in professional practice is not asking students to solve a problem presented after instruction but rather presenting an ill-defined problem before learning (20). The problem is based on the curricular content and is characterized by a beginning, a goal to be achieved, and actions needed to get from the beginning to the goal. The main difference between student-centered and teacher-centered problem solving is the student is confronted with a problem before having the information necessary to solve the problem. During clinical rotations, there are invariably plenty of opportunities for problems to arise, and students must seek out the information to solve the problem. Within the classroom, simple and complex PBL assessments can be used to mimic a professional setting and assist students in the development of positive LLL attributes, such as curiosity and persistence.

\section{EXAMPLES OF ACTIVITIES THAT PROMOTE LLL}

Early in my journey as an educator, it became evident that several students lacked the metacognitive and selfreflective skills needed in a professional nuclear medicine environment. Passing a test or a laboratory assignment did not necessarily mean that sufficient knowledge was retained and used as a building block for new knowledge. Students often struggle to grasp a holistic view of the NMT curriculum content. Students memorized information but neglected to transfer this knowledge into either the following course or the clinical experience. Additionally, the emotional responses to the expectations in a clinical environment were often negative.

The social context of the unknown negatively influenced a student's ability to critically translate classroom information into an engaged, self-regulated clinical experience. Consequently, in the spirit of LLL the teaching approach was reevaluated. A mix of simple and complex ill-defined problems was inserted into the subject-matter content curriculum with an intent focus on both cognitive and affective skill building. Some teaching interventions worked, and others failed miserably. However, they always resulted in an open discussion between faculty and students on how to improve the learning process. At this juncture, it is important to mention that classroom management and learning requires strong leadership by the instructor. Chaos theory is clearly distinguished from a devolution into total chaos and undisciplined classroom management. That said, there are opportunities for student participation in the sequencing of classroom structure and assignments...to an extent. The learning examples provided below are the result of personal experience in an associate degree, open-enrollment NMT program. Strategies taught in a bachelor degree program or a competitive enrollment program may be adjusted for the different levels of prior knowledge and academic level of the students in a given program.

Before beginning the academic coursework, students attended a student success seminar that included elements of professionalism such as time management, conflict resolution, emotional intelligence, effective communication, note taking, and summarizing reading assignments. Within the first $2 \mathrm{wk}$ of the program, a math workshop for nuclear medicine technologists was presented. Library research and writing workshops were also presented as a foundation for learning and research. The following observations and examples are anecdotal and not the results of experimental research. However, informal discussion among faculty in nuclear medicine and other health professional educational programs (i.e., sports medicine, occupational therapy, physical therapy, respiratory therapy, and nursing) helped to verify the commonalities in the observed barriers to learning when students do not know how to learn.

Aside from traditional lectures and summative testing, a mix of formative assessments was used to develop to develop LLL skills in an effort to help students overcome resistance to self-regulated, autonomous learning. A common remark often heard from students is "This is just the way I am," especially in the context of doing poorly on an assessment or when exhibiting negative professional behavior. Research assignments were met with the statement, "I can't find anything on the topic." Students relied on power points for their organization in note taking and were visibly upset when the answer to "What is on the test, midterm, or final?" was answered with the simple statement "You are responsible for all content stated in your syllabus" for a specifically defined time period. The social organization that formed in the first class of a new cohort was clearly evidenced in the seating choices, which consisted of several students grouping together in pairs or trios, with the inevitable 1 or 2 loners sitting in the back and far corners of the classroom. The examples above are not consistent with chaos theory but rather with clearly nonproductive learning capacity attributes.

A first step in establishing learning relationships was asking students to sit next to a different person in a different seat on a weekly basis. Although not a highly complex problem, to the students it was perceived as a problem with no discernible information available for analysis. The territorial imperative was alive and well in these early stages of development. Some might think this was beyond collegelevel priorities; however, the chaos created from the emotional 
anxiety proved useful as an effective teaching and learning tool. Changing and learning, adapting, coping skills, and resilience emerged from this simple exercise. Within a few weeks, a cohesive group typically emerged that relied on each other and on their own individual strengths, demonstrating both interdependent and intradependent attributes. Students and teachers became increasingly comfortable in reflecting on their own weaknesses and using their peers as a learning resource. Essentially, the sum of the parts transitioned into a better functioning interconnected group.

One example of classroom assessments used was a mix of group and individual work. Group tests were given periodically, sometimes to small groups of 2 or 3 and sometimes to the entire class. Each person received the same grade as the group. The tests were weighted less than highstakes summative individual examinations and often were graded only as extra credit points or participation points. Efforts were made by the faculty to pair academically stronger students with weaker students according to the present mastery of the subject matter. Some students were better at math whereas others excelled in the physics content. Teaching one another built the confidence needed for self-regulated behavior. In essence, penalties for learning were minimized and the focus was on final cumulative mastery of the course content evidenced in the national accreditation examination scores.

Critical curiosity was encouraged through the "30-min research" and presentation assignments. In the research assignment, students were given a broad topic such as quality assurance or instrumentation and were asked to find a representative article on the given topic and prepare a 5-min presentation. Computers for library journal article searches were readily available; therefore, time in and out of the classroom was not an issue. Also, class sizes were typically 6-12 students, so this could be easily done within one class period without jeopardizing content delivery for required, standardized outcomes. Assignments were sometimes done by a group of 2 or 3 and other times by an individual.

"The question grab bag" encouraged reading the assigned material before class time. Rather than ask questions verbally as in the Socratic method, students selected random questions from a bag to answer. Students who did not know the answer could ask the class for hints, encouraging both class discussion and the concept of vulnerability without fear in learning. Another method to model vulnerability and learning from mistakes was administering tests with ambiguously worded questions and equally ambiguous multiple-choice answers. In other words, sometimes there was more than one right answer and the students were asked to select the best choice. If a question was marked wrong, students had the option of challenging the question through a written defense. If they could demonstrate how the ambiguous wording could be analyzed and their answer made sense, they were given the point. During these discussions, there was also a discussion of the test-driven facts on a board examination. The exercise promoted critical discussion, positive conflict-resolution, and student engagement while underscoring the importance of analyzing a question for a best answer response.

The above examples are simple formative assessments that encourage engagement in the course material. Because of time restrictions, instructors often fear that these types of assignments take away from covering the required material. A well-documented option for class management is the integration of hybrid classes. Current literature in bestpractice pedagogy recommends a maximum of 15-20 min for lectures and then the introduction of an active learning exercise (21). Verbal persuasion, a component in the underpinnings of social cognitive and self-efficacy theory, is noted to be the weakest form of self-efficacy development, whereas experience is a strong proximal determinant of mastery (7). Rather than covering all the material, the literature suggests concentrating on the fundamentals and using problem-solving exercises to stimulate engagement and the reflective critical inquiry needed for LLL.

One final example of an ill-defined problem is the extended group research project. Rather than having just a final research paper, the project consisted of several deliverables throughout the semester culminating in a final paper. Again, the only information given to the student was a main topic, instructions on paper and presentation guidelines, grading rubrics, and deadlines. The project was a combination of both summative and formative assessments with deadlines set for various group and individual assignments. The final grade was dependent on a weighted mix of the various deliverables and a peer review grade from individual group members to allow students to give feedback on each teammate's participation performance and contributions. Individual deliverables included a required annotated bibliography and a draft of the student's written contribution to the final product. Groups were also required to turn in minutes of their group meetings. One observation on the importance of professional attributes incorporated into the subject-matter context was the minutes received from one group. The minutes were recorded as Tuesday 6:30 PM-8:30 PM (120 min), Friday 2:30 PM-4:00 PM (90 min). In other words, the literal minutes of the length of time of the meetings were submitted. There were no notes on information discussed, division of content, or member commitment to deadlines set by the group. This reaffirmed my philosophy of teaching, which is never to assume the prior knowledge and world experience of a student. In other words, one doesn't know what one doesn't know.

In addition, students were introduced to the foundations of group forming. Groups were selected by the instructor to guarantee a team that reflected both the weaknesses and the strengths of a team project. During the storming moments of group formation, instructors were available to facilitate conflict but students were initially encouraged to resolve conflicts among themselves before involving instructors. This process sought to model real-life behavior in a professional 
setting by following the chain of command in conflict resolution. Assertive behaviors are encouraged whereas passive-aggressive and aggressive behaviors are discouraged in the facilitation process. Learning to resolve conflicts and understanding when it is necessary to seek help for the good of the group and the project reinforces the positive behaviors expected in a diverse clinical practice.

Another important learning strategy in this type of project is the need to synthesize the individual works of each student. A common observation and a source of potential conflict was that students were reluctant to have any portion of their individual contributions removed from the final product. One rule of the project is that each individual must contribute a written portion of the final paper. Consequently, a draft of the final paper is also a required deliverable. With few exceptions, the result was that students copied and pasted each individual's written section into one final paper and turned it in with no additional editing. The drafts served as an opportunity for teachers to intervene and help students summarize and synthesize the final product, use appropriate transition sentences in paragraphs, and learn the value of editing. Students were also required to obtain a writing consult from the Writing Studio, which was staffed with writing consultants as a student resource for writing papers. Although the process was generally chaotic, the end result was a powerful learning experience in both the affective nature of learning and the cognitive research and writing experience. Deep learning of subject-matter content and a strong sense of goal achievement highlighted the benefits of this project for students.

\section{CONCLUSION}

The current status of the global learning environment underscores the paradigm shift from teacher-centered pedagogy to student-centered heutagogy. The complex, dynamic nature of today's medical technology and health care models supports the application of a heutagogic approach in professional NMT education. Self-determinism and autonomy as a learning strategy shifts the focus from knowledge acquisition to strengthening human capacity and learning power. Despite decades of research on the learning benefits of a constructive social cognitive approach and the positive benefits attributed to both teacher and student efficacy, educational and professional accountability and competency metrics act as a resistant force to change. One facet evident in the review of LLL is that knowledge is necessary for critical thought and knowledge is dependent on both affective and cognitive learner attributes.

In highlighting several aspects of learning power and through a personal experience of trial and error, the conditions of human learning as an integral component of LLL become evident. The application of a metacognitive approach to learning by both students and teachers represents a bridge between what to learn and how to learn. At the heart of a formal learning environment such as an NMT classroom are the curriculum and the assessment design. It is a given that student outcomes must include the hard facts and science necessary for content proficiency and the outcome quality necessary for board certification. The challenges in encouraging and developing LLL skills for future advocacy and professional competency lie in recognizing the need for socioemotional metrics as an integral complement to the factual knowledge of the profession and their inclusion in assessment and outcome measurements.

\section{DISCLOSURE}

No potential conflict of interest relevant to this article was reported.

\section{REFERENCES}

1. Andersen E. Learning to learn. Harvard Business Review website. https://hbr.org/ 2016/03/learning-to-learn. Published March 2016. Accessed January 30, 2019.

2. Selingo J, Simon K. The future of your career depends on lifelong learning. Forbes website. https://www.forbes.com/sites/schoolboard/2017/10/09/the-future-of-yourcareer-depends-on-lifelong-learning/\#2cda9a771bd7. Published October 9, 2017. Accessed January 30, 2019.

3. Miller TW, Gallachio VS. Allied health professionals with 2020 vision. J Allied Health. 2007;36:236-240.

4. Knight AW. How clinical instructor behavior affects student clinical behavior from a motivational perspective. J Nucl Med Technol. 2018;46:99-106.

5. Adult learning theories. LINCS website. https://lincs.ed.gov/sites/default/files/ 11_\%20TEAL_Adult_Learning_Theory.pdf. Published 2011. Accessed January 30, 2019.

6. Blaschke LM, Hase S. Heutagogy: a holistic framework for creating twenty-first century self-determined learners. In: Gros B, Kinshuk, Maina M, eds. The Future of Ubiquitous Learning: Learning Designs for Emerging Pedagogies. New York, NY: Springer; 2016:25-40.

7. Breen IT. The Influence of Perceived Organization Support on Collective Teacher Efficacy [dissertation]. Fort Lauderdale, FL: Keiser University; 2013.

8. Uggla BK. Who is the lifelong learner? Globalization, lifelong learning and hermeneutics. Stud Philos Educ. 2008;27:211-226.

9. Collins English Dictionary. Harper Collins Publishers website. https://www. collinsdictionary.com/us/dictionary/english/lifelong-learning. Accessed April 2, 2019.

10. Laal M. Lifelong learning: what does it mean? Procedia Soc Behav Sci. 2011; 28:470-474

11. Crick RD, Guoxing Y. Assessing learning dispositions: is the lifelong learning inventory valid and reliable as a measurement tool? Educ Res. 2008;50:387402.

12. Crick RD, Huang S, Shafi AA, Goldspink C. Developing resilient agency in learning: the internal structure of learning power. Br J Educ Stud. 2015;63: $121-160$.

13. Cox L, Clutter J, Sergakis G, Harris L. Learning styles of undergraduate allied health students: clinical versus classroom. J Allied Health. 2013;42:223-228.

14. Brennan C. Beyond theory and practice: a postmodern perspective. Counseling and Values. 1995;39:99-107.

15. Kantar LD. Assessment and instruction to promote higher order thinking in nursing students. Nurse Educ Today. 2014;34:789-794.

16. Dixson D, Worrell F. Formative and summative assessment in the classroom. Theory Pract. 2016;55:153-159.

17. Nuclear medicine technologist scope of practice and performance standards. SNMMI website. http://snmmi.files.cms-plus.com/docs/hpra/NMT\%20Scope\% 20of\%20Practice\%20and\%20Performance\%20Standards-2017\%20Final.pdf. Published June 2017. Accessed January 30, 2019.

18. Accreditation standards for nuclear medicine technologist education. JRCNMT website. https://www.jrcnmt.org/sites/jrcnmt2/uploads/documents/Accred_Policy_ Documents/Standards_June2018rev.pdf. Published July 1, 2018. Accessed January 30, 2019.

19. Gallagher SA, Stepien WJ, Sher BT, Workman D. Implementing problem-based learning in science classrooms. Sch Sci Math. 1995;95:136-146.

20. Greenwald NL. Learning from problems. Sci Teach. 2000;67:28-32.

21. Poirier TI. Is lecturing obsolete? Advocating for high value transformative lecturing. Am J Pharm Educ. 2017;81:83. 